\section{Dual esophageal and colon self-expanding metal stenting for colon cancer arising in esophageal interposition}

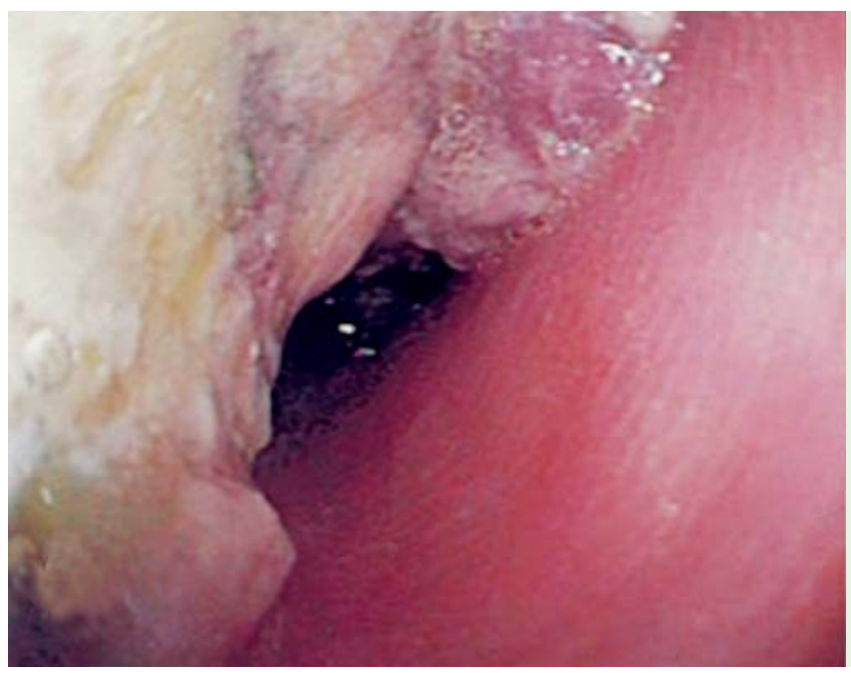

Fig. 1 Endoscopic view showing a mass in the colonic interposition that was significantly occluding the lumen.

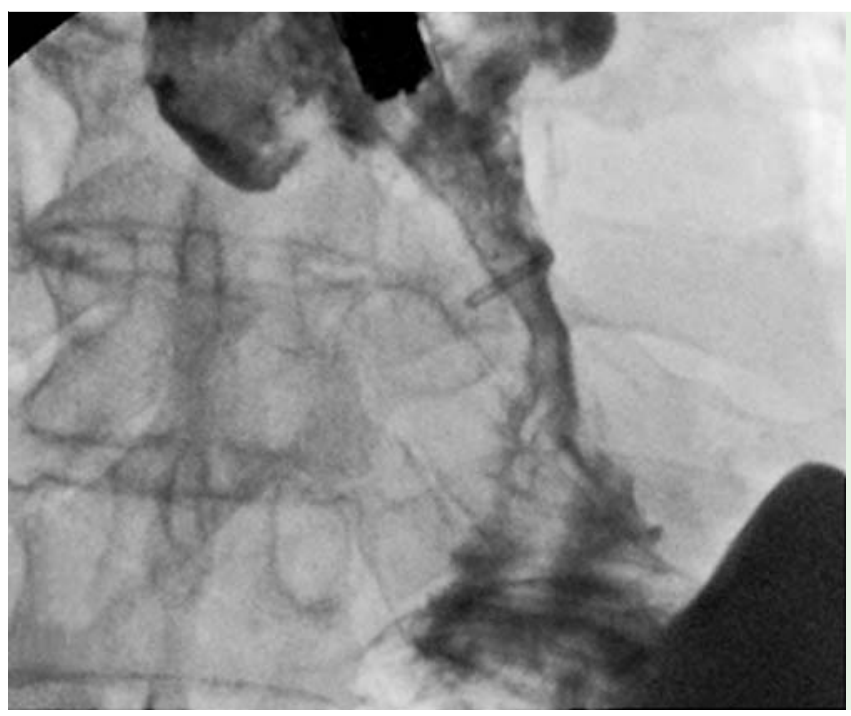

Fig. 2 The initial esophagogram of the stenotic area.

A 67-year-old man was referred for highgrade stenosis of the esophagus and metastatic adenocarcinoma. His relevant medical history included esophageal metastatic adenocarcinoma resected 10 years previously, for which he had undergone colonic interposition and chemotherapy. His risk factors included smoking one pack of cigarettes/day for over 20 years and consuming 2 ounces of alcohol/day for 30 years. He complained of progressive dysphagia to solids that had started 2 days before referral. An upper gastrointestinal series had been performed, which had been reported as a presumably malignant, high-grade stenosis of the distal esophagus adjacent to the esophagogastric junc- tion, and he was therefore referred to our center.

Esophagogastroduodenoscopy

(EGD) showed a normal esophagocolonic anastomosis and an $8 \times 5-\mathrm{cm}$ mass at the colonic interposition, which was partially occluding the esophageal lumen ( $\bullet$ Fig. 1). A contrast esophagogram performed during the EGD showed a 4-cm area of stenosis in the mid and distal neoesophagus ( $\bullet$ Fig.2). Two self-expanding metal stents were inserted. The first, a fully-covered esophageal stent $(12 \mathrm{~cm}$ in length), was placed at the cologastric anastomosis to prevent tumor ingrowth ( $\bullet$ Fig. 3 a). The second, a non-covered colonic stent $(10 \mathrm{~cm}$ in length), was placed proximally in a "stent- in-stent" fashion to anchor the covered stent ( $\bullet$ Fig. $\mathbf{3} \mathbf{b}, \mathbf{c}$ ). The stented area was endoscopically reassessed, and adequate expansion of the stents was confirmed ( $\bullet$ Fig.4). No complications arose; the patient's symptoms improved and he was discharged home the same day.

Colonic interposition replacing the esophagus was described by Kelling and Vuillet in 1911 [1,2]. It is currently used in both benign (for example, stenosis or iatrogenic fistulae) and malignant cases that warrant esophageal replacement. Acute complications include anastomotic dehiscence, fistula formation, interposed segment necrosis, and surgical site infection [3]. Longterm complications are less common, but include strictures, dumping syndrome, obstruction, gastrocolic reflux, diverticula formation, and rarely neoplasia $[4,5]$.

Endoscopic palliation of neoplasia arising from colonic interposition is tricky, as esophageal stents do not have sufficient radial expansion to expand within a "colon" lumen. In our case, this difficulty was circumvented using a double-stenting technique that involved inserting first an esophageal stent and then a colonic stent to anchor the previous one, thereby ensuring adequate proximal expansion of the colon stent within the colonic-interposition neoesophagus.

Endoscopy_UCTN_Code_TTT_1AO_2AZ

Competing interests: None

\section{P. Thomas Kröner ${ }^{1,2}$,} Klaus Mönkemüller ${ }^{2}$

1 Department of Internal Medicine, Mt. Sinai St. Luke's Roosevelt Hospital Center, New York, New York, USA

2 Basil I. Hirschowitz Endoscopic Center of Excellence, Division of Gastroenterology and Hepatology, University of Alabama at Birmingham, Birmingham, Alabama, USA

\section{References}

1 Kelling GE. Oesophagoplastik mit Hilfe der Querkolon. Zentbl f Chir 1911; 38: 12091212

2 Vuillet $H$. De l'oesophagoplastie et des diverses modifications. Sem Med 1911; 31: 529

3 Deng $B$, Wang RW, Jiang $Y G$ et al. Prevention and management of complications after colon interposition for corrosive esophageal burns. Dis Esoph 2008; 21: 57-62

4 Coopman S, Michaud L, Halna-Tamine M et al. Long-term outcome of colon interposition after esophagectomy in children. J Ped Gastro Nutr 2008; 47: 458-462

5 Spitali C, De Vogelaere K, Delvaux G. Dysphagia after colon interposition graft for esophageal carcinoma. Case Rep Path 2012; 2012: 738205 

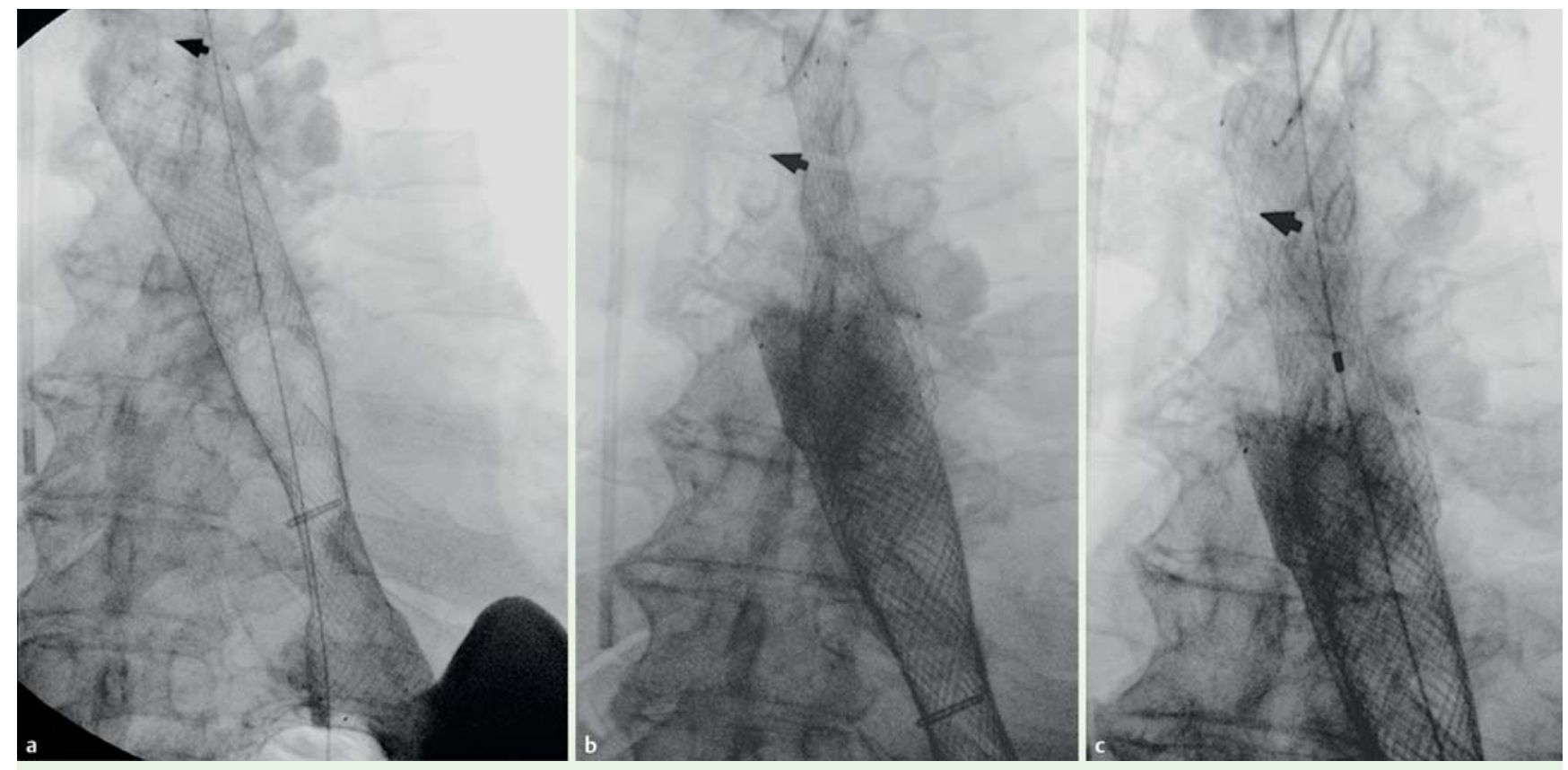

Fig. 3 Radiographic images showing: a the esophageal stent after its deployment; $\mathbf{b}$ the colonic stent being deployed in a "stent-in-stent" fashion; c the colonic stent after its placement to anchor the esophageal stent.

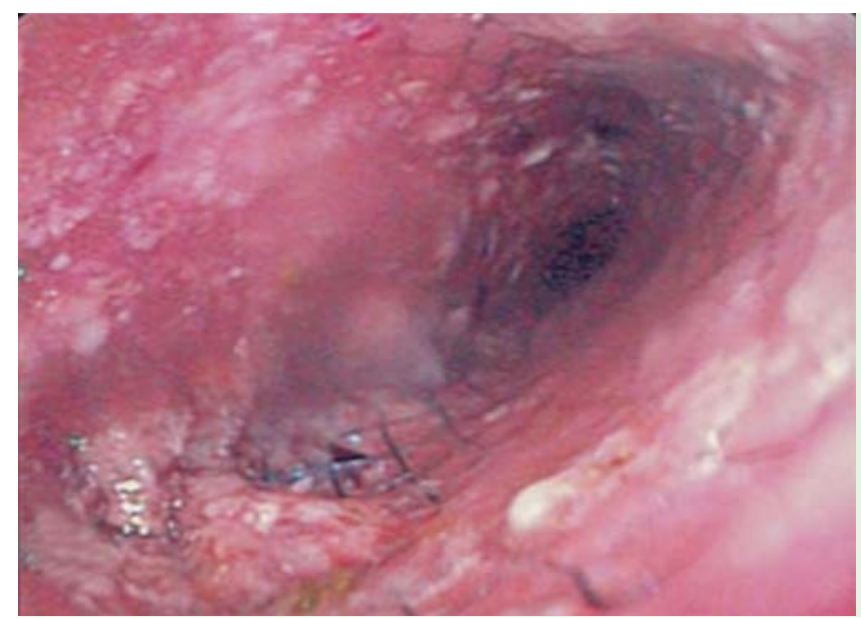

Fig. 4 Endoscopic view of the stented area confirming adequate expansion of the stents.

\section{Bibliography}

Dol http://dx.doi.org/

10.1055/s-0034-1391830

Endoscopy 2015; 47: E221-E222

(c) Georg Thieme Verlag KG

Stuttgart · New York

ISSN 0013-726X

\section{Corresponding author}

\section{P. Thomas Kröner, MD}

Mt. Sinai St. Luke's/Roosevelt Hospital Center

Department of Internal Medicine

515 W 59th

Street Apt. 15R.

New York City

NY, 10019

USA

PFlorit@chpnet.org 